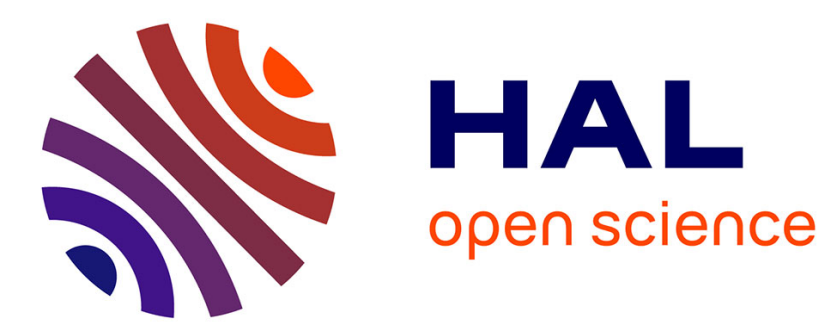

\title{
L'aristocratie languedocienne et la société féodale: le témoignage des sources (Midi de la France, XIe et XIIe siècles)
}

Hélène Débax

\section{- To cite this version:}

Hélène Débax. L'aristocratie languedocienne et la société féodale: le témoignage des sources (Midi de la France, XIe et XIIe siècles). S. Bagge, M. H. Gelting, T. Lindkvist Feudalism. New Landscapes of Debate, Brepols, pp.77-100, 2011, 978-2503531588. halshs-00498863

\section{HAL Id: halshs-00498863 \\ https://shs.hal.science/halshs-00498863}

Submitted on 8 Jul 2010

HAL is a multi-disciplinary open access archive for the deposit and dissemination of scientific research documents, whether they are published or not. The documents may come from teaching and research institutions in France or abroad, or from public or private research centers.
L'archive ouverte pluridisciplinaire HAL, est destinée au dépôt et à la diffusion de documents scientifiques de niveau recherche, publiés ou non, émanant des établissements d'enseignement et de recherche français ou étrangers, des laboratoires publics ou privés. 


\title{
L’aristocratie languedocienne et la société féodale: le témoignage des sources (Midi de la France : $\mathrm{XI}^{\mathrm{e}}$ et $\mathrm{XII}^{\mathrm{e}}$ siècles) ${ }^{1}$
}

\author{
« Keine sogennante Quelle sagt uns, \\ was der Feudalismus war (oder nicht war). \\ Das müssen wir selber zu sagen versuchen, \\ als Hypothese, der Kritik preisgegeben $»^{2}$
}

Une intervention sur le Midi de la France dans un colloque sur les espaces scandinaves pourrait paraître déplacée. À certains égards, cependant, sur le plan historiographique, cette région ne se trouve pas dans une situation très éloignée de celle des pays nordiques. Le Midi lui aussi a été longtemps considéré comme une périphérie, à la marge des vieux pays francs. On estimait qu'il n'avait connu les évolutions que tardivement et imparfaitement. Le modèle était non une kinship society comme pour les espaces scandinaves, non une société gentilice comme en Espagne du nord-ouest, mais une société d'amis et d'égaux, dominée de très haut par de quasi-rois, les comtes de Toulouse ${ }^{3}$. Ce qu'il est convenu d'appeler la féodalité classique, c'est-à-dire en simplifiant le modèle de Ganshof, la «féodalité d'entre Loire et Rhin », a longtemps été considéré comme s'appliquant mal au Midi de la France. Robert Boutruche en 1970 estimait les féodalités méridionales inachevées et épidermiques, or André Debord dans sa synthèse posthume sur l'aristocratie publiée en 2000 affirmait : «il paraît acquis que la zone la plus précocément féodalisée a été le monde méditerranéen, passée la crise du premier tiers du $\mathrm{XI}^{\mathrm{e}}$ siècle ${ }^{4}$. En 30 ans, le retournement est spectaculaire.

C'est qu'entre temps avait paru un certain nombre de monographies décrivant une société méridionale qui avait elle aussi connu une évolution féodale, en Catalogne, en Provence, en Biterrois ou en Languedoc ${ }^{5}$. Ces nouvelles analyses sociales ont amené à discuter le modèle classique : beaucoup d'éléments de l'étude de Ganshof ne cadraient pas avec les réalités méridionales, mais cela tenait surtout au schématisme de ce petit manuel qui avait rassemblé et présenté comme un tout des éléments disparates et non contemporains les

\footnotetext{
${ }^{1}$ Tous mes remerciements vont à Dominique Baudreu, Jean-Paul Cazes, Florent Hautefeuille, Mireille Mousnier, Didier Panfili, Gérard Pradalié et Laurent Schneider, qui ont eu l'amabilité de m'aider, en particulier pour la cartographie.

2 Ludolf Kuchenbuch, "Feudalismus": Versuch über die Gebrauchstrategien eines wissenspolitischen Reizwortes », Die Gegenwart des Feudalismus, Présence du féodalisme et présent de la féodalité, The Presence of Feudalism, P. Monnet N. Fryde, O. G. Oexle (éd), Vandenhoeck \& Ruprecht, Göttingen, 2002, p. 323. («Aucune source ne nous dit ce qu'était le féodalisme ou ce qu'il n'était pas. Cela, nous devons chercher à le dire nous-mêmes, comme une hypothèse livrée à la critique »).

${ }^{3}$ Elisabeth Magnou-Nortier, La société lä̈que et l'Église dans la province ecclésiastique de Narbonne, de la fin du VIII à la fin $d u X^{e}$ siècle, Toulouse, 1974 ; Paul Ourliac, «Réalité ou imaginaire : la féodalité toulousaine », Mélanges Jacques Ellul, Paris, 1983, p. 331-344.

${ }^{4}$ Robert Boutruche, Seigneurie et féodalité. II. L'apogée, XI $-X I I I^{e}$ siècles, Aubier, Paris, 1970, p. 313. André Debord, Aristocratie et pouvoir. Le rôle du château dans la France médiévale, Picard, Paris, 2000, p. 138.

${ }^{5}$ Pierre Bonnassie, La Catalogne du milieu du X à la fin du XI siècle, croissance et mutations d'une société, Publications de l'Université de Toulouse le Mirail, Toulouse, 1975-1976. Jean-Pierre Poly, La Provence et la société féodale (879-1166), Bordas, Paris, 1976. Monique Bourin-Derruau, Villages médiévaux en BasLanguedoc : genèse d'une sociabilité ( $X^{e}-X I V^{e}$ siècle), L'Harmattan, Paris, 1987. Gérard Giordanengo, Le droit féodal dans les pays de droit écrit, l'exemple de la Provence et du Dauphiné (XII -début XIV siècles), BEFAR 266, École Française de Rome, 1988. Claudie Duhamel-Amado, Genèse des lignages méridionaux, Collection Méridiennes, CNRS-Université Toulouse II-Le Mirail, Toulouse, t. 1, 2001 et t. 2, 2007. Hélène Débax, La féodalité languedocienne. Serments, hommages et fiefs dans le Languedoc des Trencavel, PUM, Toulouse, 2003.
} 
uns des autres. La féodalisation du Midi n'a pu être suggérée que par une réflexion sur ce qu'on pouvait entendre sous le terme de société féodale.

Il va donc s'agir ici de présenter les «caractères originaux » de la société féodale méridionale aux $\mathrm{XI}^{\mathrm{e}}-\mathrm{XII}^{\mathrm{e}}$ siècles, une société qui n'est conforme ni au modèle de Ganshof, ni au modèle des feudistes ${ }^{6}$. Vu l'ampleur du sujet, tout ne pourra être traité; nous nous attacherons particulièrement aux strictes relations féodo-vassaliques, c'est-à-dire aux questions juridiques et institutionnelles, pour tenter de comprendre les modalités de l'exercice du pouvoir. En raison de la richesse du sujet et de l'abondance des sources, il ne sera question que de l'aristocratie castrale, cette classe de seigneurs, grands, moyens et petits qui contrôlent des castra, ou des parts de castra. Nous développerons donc non une réflexion générale et théorique, mais un cas régional, pour qu'il soit versé au dossier dans le débat collectif.

Après avoir brièvement présenté la région étudiée, d'un point de vue géographique et historique, nous exposerons la typologie de la documentation qui renseigne sur l'aristocratie castrale du Languedoc aux $\mathrm{XI}^{\mathrm{e}}$ et $\mathrm{XII}^{\mathrm{e}}$ siècles. Nous exposerons ensuite quelques réflexions sur le fonctionnement du fief et de la vassalité dans cette zone.

La région considérée se situe dans le sud du royaume de France, entre la Garonne et le Rhône, de Toulouse à Nîmes, et entre les Pyrénées et les contreforts méridionaux du Massif central. Bien qu'il appartienne au royaume, ce Languedoc est totalement hors de l'influence effective du roi de France entre les années 940 et la deuxième moitié du XII ${ }^{\mathrm{e}}$ siècle. Les dernières traces de présence de méridionaux à la cour de France ou de lien personnel entre le roi et les représentants locaux du pouvoir datent du milieu du $\mathrm{X}^{\mathrm{e}}$ siècle ${ }^{7}$. Les premières timides interventions capétiennes ne datent que de la deuxième moitié du XII ${ }^{\mathrm{e}}$ siècle, quand Louis VII partit en pèlerinage à Saint-Jacques de Compostelle, avant, bien entendu, la grande intrusion du début du XIII ${ }^{\mathrm{e}}$ siècle, la croisade dite albigeoise ${ }^{8}$. Les $\mathrm{XI}^{\mathrm{e}}$ et $\mathrm{XII}^{\mathrm{e}}$ siècles sont donc une période d'absence royale, qu'en est-il des pouvoirs locaux ? Au niveau supérieur, on éprouve un peu de mal à saisir le pouvoir et l'action des comtes.

Les comtes de Toulouse ont une autorité théorique sur le Languedoc, grâce à leur titre de marquis de Gothie : outre Toulouse, Albi, Cahors et Rodez, ils dominent l'ancienne Septimanie wisigothique, les comtés de Nîmes, Agde, Béziers, Lodève et Narbonne. Ils doivent compter avec deux autres dynasties comtales : les comtes de Carcassonne, jusqu'en 1067-1068, et les comtes de Melgueil, dont la lignée s'éteint en 1176. Ces lignées comtales, toutes puissantes au $\mathrm{X}^{\mathrm{e}}$ siècle, subissent une nette érosion de leurs capacités d'action au $\mathrm{XI}^{\mathrm{e}}$ siècle, menacées par la réorganisation locale des pouvoirs autour des châteaux ${ }^{9}$. Les comtes ont surtout affaire partout à des vicomtes qui prennent leur autonomie entre $\mathrm{X}^{\mathrm{e}}$ et $\mathrm{XI}^{\mathrm{e}}$ siècle. $\mathrm{Au} \mathrm{X}^{\mathrm{e}}$ siècle encore, ces délégués que les comtes ont nommés dans chacun de leurs comtés apparaissent régulièrement dans l'entourage comtal et souscrivent aux actes comtaux. Au XI siècle en revanche, ils s'affranchissent de l'orbite comtale et on ne voit plus les comtes

\footnotetext{
${ }^{6}$ Sur la construction du corpus de ces spécialistes du droit féodal, voir : Gérard Giordanengo, «Les feudistes (XII ${ }^{\mathrm{e}}-\mathrm{XV}^{\mathrm{e}}$ siècles) », El dret comú $i$ Catalunya, Aquilino Iglesia Ferreiros (éd.), Fundació Noguera, Barcelona, 1992, p. 67-144.

${ }^{7}$ Jean-François Lemarignier, «Les fidèles du roi de France », Recueil de travaux offerts à Clovis Brunel, t. II, Paris, 1955, p. 138-162. La tentative de Robert le Pieux pour renouer avec la partie sud de son royaume dans les années 1020 est un échec politique : Christian Lauranson-Rosaz, L'Auvergne et ses marges (Velay, Gévaudan) du VIII $e^{e}$ au XI ${ }^{e}$ siècle, la fin du monde antique ?, Les Cahiers de la Haute-Loire, Le Puy en Velay, 1987, p. 442456.

${ }^{8}$ Le point le plus récent, avec la bibliographie antérieure, se trouve dans: La croisade albigeoise, Centre d'études cathares, Carcassonne, 2004.

${ }^{9}$ Hélène Débax, «L'aristocratie méridionale autour de 1100 », L'aristocratie, les arts et l'architecture à l'époque romane, Cahiers de Saint-Michel de Cuxa, Actes des XXXVI Journées romanes, 2005, p. 7-20.
} 
intervenir dans les zones contrôlées par les vicomtes ${ }^{10}$. Ces vicomtes, ce sont les Trencavel installés en Albigeois et à Nîmes, puis à Béziers, Agde, Carcassonne et Razès, et les vicomtes de Narbonne qui tiennent la zone côtière au nord du Roussillon. Dans le sud du Rouergue, on assiste à l'ascension des vicomtes de Millau, qui deviennent comtes au tout début du XII ${ }^{\mathrm{e}}$ siècle. D'autres dynasties, avec ou sans titre, imposent leur pouvoir plus localement, les vicomtes de Minerve (en Narbonnais) ou de Lautrec (en Albigeois), les seigneurs d'Anduze (comté de Nîmes), de Montpellier (comté de Melgueil) ou de Termes (dans les Corbières).

Donc, en Languedoc aux $\mathrm{XI}^{\mathrm{e}}-\mathrm{XII}^{\mathrm{e}}$ siècles, il n'y a pas de roi, on rencontre des comtes assez évanescents, des vicomtes et des barons, et surtout une floraison exceptionnelle de châteaux et de seigneuries castrales. À partir des années 980 environ, les châteaux se multiplient dans la documentation. En Languedoc, on peut véritablement parler de «castellisation» ou de "castralisation» des paysages ${ }^{11}$. Le relief s'y prête : la plus grande partie de la zone étudiée est une région de moyenne montagne ou de plateaux entaillés par de profondes vallées, où les pays sont très cloisonnés. Il n'y a qu'une étroite plaine sur le littoral méditerranéen, et dans le couloir du Lauragais. Partout, sur de petits reliefs, des rebords de vallées ou des pitons rocheux, ont surgi des tours. Le phénomène apparaît très clairement si l'on compare deux cartes : celles des châteaux attestés aux $\mathrm{IX}^{\mathrm{e}}-\mathrm{X}^{\mathrm{e}}$ siècles et celle des châteaux attestés aux $\mathrm{XI}^{\mathrm{e}}-\mathrm{XII}^{\mathrm{e}}$ siècles $^{12}$ [voir les deux cartes en annexe]. À l'époque carolingienne et post-carolingienne, il y a peu de châteaux attestés, entre 5 et 10 environ par comté, et cela, dans une relative abondance de la documentation. J. Belmon a pu dénombrer environ un millier de chartes pour les $\mathrm{IX}^{\mathrm{e}}$ et $\mathrm{X}^{\mathrm{e}}$ siècles, avec entre autres une bonne dizaine de testaments de membres de familles comtales ou vicomtales dans la deuxième moitié du $\mathrm{X}^{\mathrm{e}}$ siècle. En regard, la profusion des châteaux aux $\mathrm{XI}^{\mathrm{e}}$ et $\mathrm{XII}^{\mathrm{e}}$ siècles est telle qu'elle défie toute cartographie à la même échelle. Dans certaines zones, il est impossible de faire figurer toutes les structures fortifiées attestées : la carte doit être comprise comme une évocation et non comme une réelle géographie des châteaux qui demanderait un niveau de représentation beaucoup plus précis. Par ailleurs, les anciennes structures d'encadrement des populations qu'étaient le ministerium, la vicaria, le pagus ou l'aice, disparaissent alors des sources et sont remplacées par le terminium ou le territorium castri $^{13}$. À la tête de tous ces petits châteaux, on

\footnotetext{
${ }^{10}$ Vicomtes et vicomtés dans l'Occident médiéval, Actes du colloque d'Albi, 6-8 octobre 2006, H. Débax (éd.), Toulouse, Presses Universitaires du Mirail, à paraître en 2007.

${ }^{11}$ Joseph Morsel, L'aristocratie médiévale, Armand Colin, Paris, 2004, p. 88-115.

${ }^{12}$ Les cartes ont été composées grâce aux travaux de Claudie Amado (op.cit.), Dominique Baudreu («Le BasRazès aux $\mathrm{XI}^{\mathrm{e}}-\mathrm{XII}{ }^{\mathrm{e}}$ siècles. Formes castrales et ecclésiales de l'habitat groupé », Histoire et archéologie des terres catalanes au Moyen Age, P. Sénac (éd), Perpignan, 1995, p. 187-228), Jérôme Belmon (Les vicomtes de Rouergue-Millau (Xe-XIe siècles), Thèse dactylographiée, École Nationale des Chartes, 1991), Monique Bourin (op.cit.), Jacqueline Caille (Medieval Narbonne. A City at th Heart of the Troubadour World, Ashgate Variorum, 2005), Sylvie Campech («L'occupation du sol au Moyen Age sur le piémont nord de la montagne noire (Tarn) », Archéologie du Midi médiéval, T. VII, 1989, p. 43-59), Jean-Paul Cazes (Habitat et occupation du sol en Lauragais audois au Moyen Age, doctorat nouveau régime dactyl., Université Toulouse II-Le Mirail, 1998), André Debord («Châteaux et société dans le Rouergue médiéval (X $\left.{ }^{\mathrm{e}}-\mathrm{XIII}{ }^{\mathrm{e}}\right)$ », Château-Gaillard 14, Caen, 1990, p. 7-28), Aline Durand (Les paysages médiévaux du Languedoc (X $X^{e}$-XII siècles), Presses Universitaires du Mirail, Toulouse, 1998), Frédéric de Gournay (Le Rouergue au tournant de l'an mil. De l'ordre carolingien à l'ordre féodal (IX $-X I I^{e}$ siècle), Collection Méridiennes, Toulouse, 2004), Florence Journot ("Châteaux du Languedoc montagnard», Archéologie du Midi médiéval, Tome X, 1992, p. 39-62), Mireille Mousnier (La Gascogne toulousaine aux XII ${ }^{e}$-XIII ${ }^{e}$ siècles. Une dynamique sociale et spatiale, Presses Universitaires du Mirail, Toulouse, 1997), Christian Raynaud («Villages disparus dans les Pyrénées audoises : les mutations médiévales de l'habitat », Annales du Midi, 1986, p. 433-467), Laurent Schneider («Dans l'ombre de Montpellier. Espace, pouvoir et territoires dans l'ancien pagus de Maguelone durant le haut Moyen Age $\left(\mathrm{V}^{\mathrm{e}}-\mathrm{XI}^{\mathrm{e}}\right.$ siècles) », Carte archéologique de la Gaule 34/3. Le Montpelliérais, Paris, 2003, p. 98-112).

${ }^{13}$ Le constat de l'explosion du nombre de châteaux à partir du $\mathrm{XI}^{\mathrm{e}}$ siècle et de l'absence de continuité des cadres territoriaux anciens avait été fait pour le Rouergue par André Debord («Châteaux et société dans le Rouergue médiéval $\left(\mathrm{X}^{\mathrm{e}}-\mathrm{XIII}^{\mathrm{e}}\right)$ », Château-Gaillard 14, Najac (France), Caen, 1990, p. 7-28).
} 
rencontre une multitude de seigneurs pour lesquels on a conservé une abondante documentation : celle-ci va maintenant nous intéresser.

L'essentiel des sources utilisées sont des sources diplomatiques, conservées à la fois dans des cartulaires et à l'état d'originaux.

La documentation des cartulaires ${ }^{14}$

$\mathrm{XI}^{\mathrm{e}}$ siècle

\begin{tabular}{|c|c|c|c|c|c|}
\hline & serments & sécurités & inféodations & reprises & reconnaissances \\
\hline Trencavel & 96 & 5 & 3 & 7 & \\
\hline Montpellier & 15 & 1 & 1 & & \\
\hline \multicolumn{6}{|l|}{ Maguelone } \\
\hline Agde & & 1 & & & \\
\hline Béziers & & & 4 & & \\
\hline Saint-Sernin & & & 1 & & \\
\hline Aniane & & & & 1 & \\
\hline Gellone & & & 3 & 5 & \\
\hline Lagrasse & & & 2 & & 1 \\
\hline \multicolumn{6}{|l|}{ Douzens } \\
\hline HGL & 9 & 7 & 2 & & \\
\hline total $\mathrm{XI}^{\mathrm{e}}$ & 120 & 14 & 16 & 13 & 1 \\
\hline
\end{tabular}

$\mathrm{XII}^{\mathrm{e}}$ siècle

\begin{tabular}{|c|c|c|c|c|c|}
\hline Trencavel & 201 & 41 & 63 & 20 & 8 \\
\hline Montpellier & 103 & 14 & 27 & 14 & 11 \\
\hline Maguelone & 20 & 1 & 12 & 5 & 11 \\
\hline Agde & & 3 & 3 & & 4 \\
\hline Béziers & 1 & & & & 2 \\
\hline Saint-Sernin & & & 4 & 2 & 3 \\
\hline Aniane & 5 & & 5 & 13 & \\
\hline Gellone & & 2 & 4 & 4 & 3 \\
\hline Lagrasse & 2 & 2 & 1 & 1 & \\
\hline
\end{tabular}

14 Trencavel : cartulaire inédit, Société archéologique de Montpellier, ms. 10 ; Montpellier : A. Germain, Cartulaire des Guilhem de Montpellier. Liber Instrumentorum Memorialium, Montpellier, 1884-1886; Maguelone: J Rouquette et A. Villemagne, Cartulaire de Maguelone, Montpellier, 1912 ; Agde : O. Terrin, Cartulaire du Chapitre d'Agde, Nîmes, 1969 et Raymonde Foreville, Le cartulaire du chapitre cathédral d'Agde, CNRS Editions, Paris, 1995 ; Béziers : J. B. Rouquette, Cartulaire de Béziers, Livre Noir, Paris-Montpellier, 1918-1922 ; Saint-Sernin : Mgr C. Douais, Cartulaire de l'abbaye de Saint-Sernin de Toulouse, Paris, 1887 et P. et T. Gérard, Cartulaire de Saint-Sernin de Toulouse, Toulouse, 1999 ; Aniane : abbé L. Cassan et E. Meynial, Cartulaire des abbayes d'Aniane et de Gellone, Cartulaire d'Aniane, Montpellier, 1900 ; Gellone : P. Alaus, abbé L. Cassan et E Meynial, Cartulaire des abbayes d'Aniane et de Gellone, Cartulaire de Gellone, Montpellier, 1897 ; Lagrasse : E. Magnou-Nortier et A.-M. Magnou, Recueil des chartes de l'abbaye de Lagrasse, tome I, Éditions du CTHS, Paris, 1996 et C. Pailhès, Recueil des chartes de l'abbaye de Lagrasse, tome II, Éditions du CTHS, Paris, 2000 ; Douzens : Pierre Gérard et Elisabeth Magnou, Cartulaire des Templiers de Douzens, B.N., Paris, 1965 ; HGL : Dom Cl. Devic et Dom J. Vaissète, Histoire Générale de Languedoc, rééd. Privat, Toulouse, 1872-1902. 


\begin{tabular}{|c|c|c|c|c|c|}
\hline Douzens & & & & & 2 \\
\hline HGL & 42 & 14 & 16 & 13 & 12 \\
\hline total XII $^{\mathrm{e}}$ & 374 & 77 & 135 & 72 & 56 \\
\hline
\end{tabular}

\begin{tabular}{|l|l|l|l|l|l|}
\hline TOTAUX & 494 & 91 & 151 & 85 & 57 \\
\hline
\end{tabular}

Les cartulaires sont très nombreux en Languedoc. On connaît maintenant assez bien leurs dates et leurs modalités de composition grâce aux travaux de Pierre Chastang, grâce aussi au colloque qu'a publié l'École des chartes sur les cartulaires méridionaux ${ }^{15}$. Le tableau composé à partir de leur dépouillement exhaustif dénombre les actes qui renseignent sur le fief et sur le lien féodo-vassalique. On peut souligner que la grande originalité du Languedoc est d'avoir conservé deux magnifiques cartulaires laïques, celui des Guilhem de Montpellier et celui des Trencavel. Remarquons que ce sont ces sources laïques qui fournissent la très grande majorité des occurences. Le dépouillement parallèle des cartulaires ecclésiastiques montre que les procédures féodales ne sont pas inconnues des évêques ou des abbés, mais beaucoup moins pratiquées. Le premier corpus, Maguelone, est à mettre un peu à part car cette compilation d'actes - qui n'est pas un véritable cartulaire - concerne à la fois les évêques et le chapitre, mais aussi les comtes de Melgueil. Agde, Béziers et Saint-Sernin de Toulouse sont des cartulaires canoniaux. Aniane, Gellone et Lagrasse sont trois gros fonds d'archives de trois anciennes abbayes bénédictines, deux cartulaires et un chartrier. Le dernier cas est un test fait sur un cartulaire templier, celui de la commanderie de Douzens, proche de Carcassonne. En dernière ligne, on trouve l'inventaire d'un certain nombre de textes épars, publiés au XVIII ${ }^{\mathrm{e}}$ siècle dans la monumentale compilation, l'Histoire générale de Languedoc, de dom Devic et dom Vaissète (actes publiés à partir de sources aujourd'hui disparues, concernant essentiellement les comtes de Toulouse, les comtes de Foix, et les vicomtes de Narbonne, pour lesquels ont n'a pas conservé de fonds propre d'archives). Ce tableau pourrait être complété grâce au cartulaire des comtes de Barcelone qui ont contrôlé à certains moments les comtés de Carcassonne, Razès, Rodez, les vicomtés de Milau et de Carlat et le Gévaudan.

Les données fournies par les cartulaires peuvent être comparées et contrôlées grâce à un grand nombre d'originaux, conservés pour la plupart aux Archives nationales dans le Trésor des chartes des rois de France ${ }^{16}$. Ce sont des archives issues des comtes de Toulouse, des vicomtes de Nîmes et de nombreuses petites seigneuries sous leur domination. Ces originaux très nombreux - plusieurs centaines assurément - n'ont pas été exhaustivement recensés, mais plusieurs seront utilisés ponctuellement. Ici aussi, il faudrait compléter le dépouillement grâce aux originaux des archives comtales barcelonaises qui sont en grande partie encore inédits ${ }^{17}$.

Une première observation d'ensemble peut être faite à propos de ces chiffres bruts : le lien féodo-vassalique est révélé de façon très majoritaire par les sources laïques. Le serment pour un château ou son inféodation ne sont pas des types d'actes inconnus des institutions ecclésiastiques, mais on n'en a de témoignage que lorsque cette institution peut être représentée par un homme seul, un évêque ou un abbé. Quelques textes ont donc pu être glanés dans des corpus d'actes épiscopaux ou abbatiaux. Les structures collectives comme les chapitres, ou bien pour d'autres raisons, celles qui se sont organisées tardivement, au XII ${ }^{\mathrm{e}}$

\footnotetext{
${ }^{15}$ Pierre Chastang, Lire, écrire, transcrire. Le travail des rédacteurs de cartulaires en Bas-Languedoc (XIe-XIIIe siècles), Éditions du CTHS, Paris, 2001 ; Daniel Le Blévec (éd.), Les cartulaires méridionaux, Études et rencontres de l'Ecole des chartes, Paris, 2006.

${ }^{16}$ Paris, Archives Nationales, Trésor des Chartes, J 300 à J 335.

${ }^{17}$ Une première publication : Gaspar Feliu et Josep Maria Salrach, Els pergamins de l'Arxiu comtal de Barcelona de Ramon Borell a Ramon Berenguer I (981-1076), Fundació Noguera, Barcelone, 1999.
} 
siècle, comme les Templiers ou les Hospitaliers, ne reçoivent pas de serment et contrôlent d'ailleurs très peu de châteaux. Le test sur les Templiers de Douzens est significatif, et pourrait être corroboré par les autres fonds documentaires templiers ou hospitaliers. Quand ces ordres nouveaux se sont installés, les cellules banales et castrales étaient organisées, et les réseaux constitués : ils eurent beaucoup de difficultés à s'insérer au niveau de la seigneurie castrale.

Les chartes pertinentes pour cerner le lien féodo-vassalique peuvent être ordonnées en une typologie souple, autour des deux pôles que constituent les serments et les inféodations.

C'est une des grandes spécificités des régions méditerranéennes, de la Provence à la Catalogne et du Cantal au Languedoc que d'avoir conservé de très nombreux textes de serments pour des châteaux - pas seulement la mention du fait qu'un serment a été prêté mais le contenu-même des engagements. Il s'agit d'un type d'acte tout à fait nouveau au XI siècle. Environ 500 serments ont pu être dénombrés dans le corpus des cartulaires pour les deux siècles envisagés, mais ce chiffre pourrait être pratiquement doublé en prenant en compte les actes catalans et provençaux. Voici l'un de ces textes, un serment pour le castellum de Roquefort-sur-le-Sor (Tarn), prêté à un vicomte Trencavel, avant 1030 :

De ista hora in antea no decebra Ugo filius Ermengarz. Atonem filium Gauciane de illo castello qui vocatur Rocafort qui est in ribera de Sor, ni de ipsas turres, ni de ipsas fortezas que ibi hodie facte sunt aut in antea facte erunt, nec ipse Ugo, nec homo nec femina pro suum ingenium nec pro suum consilium, ni nolli tolra, ni nolli devedara ipse Ugo ad ipsum Atonem, ni ab forfacto ni sine forfacto, et si est homo vel femina qui ipsum castellum Rocafort tollat o devedad Atonem filium Gauciane, Ugo filius Ermengard ab illo homine vel ab illa femina societatem non tenra, ni finem no fara, incontra dampnum de ipso Atone, intro recuperatum habeat Ato ipsum castellum de Rocafort, in adjutorium li erit Ugo ad ipsum Atonem sine ulla deceptione, et si ipse Ugo ipsum castellum recobrare potuerit, in potestate Atone lo metra sine inganno et sine lucro, sicut in isto pergameno superius scriptum est, si o tenra et si o atendra ipse Ugo filius Ermengard incontra Atonem filium Gauciane de ipso castello de Rocafort, fors quantum ipse Ato len absolvra ad ipsum Ugonem suo gradiente animo sine forcia ${ }^{18}$.

Dans ces serments, l'essentiel est qu'un homme s'engage envers un autre à propos d'un château. Il lui promet de ne pas le tromper, de ne pas lui enlever le château, de le lui rendre, et de lui fournir une aide. Les termes de la promesse sont ancrés dans la réalité matérielle du castrum. Un exemple à peine postérieur et tout à fait comparable peut être pris dans la famille des seigneurs de Montpellier : il s'agit d'un serment pour le castrum du Pouget (Hérault), prêté vers 1068-1090 :

De ista hora in antea, ego Girundes filis Advenia non decebrai Vilelmum filium Ermenjardis de ipso castro quod vocatur Pojet, nun li tolrai ni len tolrai, ni li vedarai ni len vedarai, de illas fortezas que ara $i$ son ni adenant $i$ erun, ni hom ni femena per meun ingen ni per meu art ni per meu unsel. E si hom era u femena quel ti tulgues $u$ ten tulgues, cum illis finem nec societatem non aurai al daun de Vilelmo suprascripto ad adjuderai ad Vilelmum suprascriptum usquequo habuisset recuperatum; et cum

\footnotetext{
${ }^{18}$ Cartulaire des Trencavel, acte 49, fol. 12.
} 
illo et sine illo adjudar len ai par fidem et sine inganno et rendrai lol per achelas vez que men cumonra per se u per sun mes u per sus misos sine suo inganno et sine sua deceptione e del comoniment num vederai ${ }^{19}$.

Ces actes sont informes d'un point de vue diplomatique et sont rédigés dans une langue très marquée par la langue vernaculaire, l'occitan: on peut penser qu'elle témoigne assez fidèlement de ce qui pouvait être réellement dit. On possède en effet des actes contemporains comme des chartes de donation, des ventes ou des testaments qui sont rédigés en latin et qui respectent globalement le formulaire diplomatique. Cela veut dire que la forme particulière des serments est une forme délibérée, que l'on ne peut expliquer par la méconnaissance des formulaires et encore moins par un oubli du latin ${ }^{20}$. Cette langue très proche de l'oralité montre que la féodalité languedocienne est une féodalité pragmatique et intériorisée, qui n'est pas imposée de l'extérieur, ni calquée sur des modèles normatifs -comme les Libri Feudorum, qui d'ailleurs n'existent pas encore.

Deux éléments ont jusqu'à présent empêché d'apprécier la spécificité de ces serments et de leur donner une juste place dans la compréhension du fonctionnement de l'aristocratie méridionale. Ces serments pour un château ont été rapprochés à tort de quelques serments conservés pour le $\mathrm{X}^{\mathrm{e}}$ siècle qui n'ont strictement aucun rapport, sauf leur nature sacramentelle ${ }^{21}$. Les serments pour un château, tels que les deux présentés ci-dessus, sont une forme nouvelle au $\mathrm{XI}^{\mathrm{e}} \mathrm{s}$, les premiers conservés sont les onze serments au vicomte Aton II d'Albi (Trencavel) ou à son frère (entre 990 et 1030), les trois à Bérenger, vicomte de Narbonne (à partir des années 1020), et un serment à l'évêque de Rodez (à l'extrême fin du X $\mathrm{X}^{\mathrm{e}}$ siècle). Un deuxième élément a généré le brouillage des catégories : ces serments pour un château ont été jugés répétitifs et tous identiques, et de ce fait ils ont souvent été édités de façon tronquée (avec de multiples «etc. » dans l'Histoire générale de Languedoc qui en a été le principal éditeur). Cela a entraîné une confusion avec une autre catégorie de serments que l'on rencontre aussi fréquemment dans la documentation languedocienne, les sécurités. Dans ce que l'on peut appeler les sécurités, il n'y a pas d'engagement pour un château. Celui qui jure promet simplement de ne pas attaquer la personne de l'autre, ou ses biens : il s'agit d'une sécurité personnelle, un serment qui ressortit aux catégories de l'alliance. À la différence du serment pour un château, la sécurité n'instaure aucune hiérarchie et elle est bien souvent réciproque. Elle peut aussi sceller des alliances offensives (on promet d'aider l'autre contre quelqu'un). Dans le contexte de la grande guerre méridionale du XII ${ }^{\mathrm{e}}$ siècle, on conserve des sécurités entre tous les comtes, vicomtes et grands seigneurs du Midi, au gré des alliances et des ligues créées, pour ou contre Toulouse, pour ou contre Barcelone. La confusion a été accentuée par le fait que parfois de telles sécurités viennent en introduction d'un serment pour un château. Celui qui jure promet d'abord de ne pas attaquer la personne de l'autre, puis il promet de lui rendre un château. Un seul exemple sera présenté, un serment pour les castella de Lunas (Hérault), prêté à Frotaire, frère d'Aton II, avant 1014 :

De ista hora in antea non decebra Deusde filius Adalaiz Froterium filium Gaucia de sua vita ni de sua membra que in corpus suum portat et in corpus suum se tenet per que ille o perda, ni non fara ni non consentira sua presione a suo dampno suo sciente,

\footnotetext{
${ }^{19}$ A. Germain, LIM, acte 484.

${ }^{20}$ Voir à ce propos: Philippe Martel, «Les chartes en occitan du XII ${ }^{\mathrm{e}}$ siècle. Une anomalie ? ", Langues, dialectes et écritures : les langues romanes en France, sous la direciton de Hervé Guillotel et Jean Sibile, Paris, 1993, p. 17-29.

${ }^{21}$ Comme par exemple le serment du bayle de l'abbaye de Camon en 950, ou bien le serment aux chanoines de Brioude des environs de l'an mil, qui s'apparente très fortement aux serments de la Paix de Dieu (voir E. Magnou-Nortier, La société laïque..., op. cit.).
} 
ni nol decebra ni nol devedara ni nol tolra illos castellos de Lunatis ni illas turres ni illos muros ni illas fortezas que hodie $i$ sunt et in antea erint, ni Deusde ni hom ni femna per suo consilio ni per suo consilio ni per suo ingenio nec per sua consencia, et si homo est aut femna qui Froterio tollat ipsos castellos suprascriptos aut ipsas turres aut ipsas fortezas, Deusde cum illo homine aut cum illa femina qui hoc fecit societatem non tenra ad dampno de Froterio suo sciente, usque recuperatum habeat ipsum castellum, nisi quantum Froterius illum absolvera sine forcia, et in adjutorium erit Deusde de illos aut de illas qui hoc fecerint ad Froterio sine sua deceptione, et si Deusde recuperare potuerit ipsum castellum, in potestate Froterii lo tornara sine lucro et sine ulla deceptione Froteri $i^{22}$.

Si l'on élabore une typologie détaillée de tous ces serments languedociens et si on considère les textes in extenso, on ne peut plus affirmer que les serments pour un château sont de simples pactes de non agression qui ne comprendraient que des obligations négatives. On y trouve toujours, dès les premiers textes conservés, une promesse très claire de fournir un adjutorium, une aide militaire, qui parfois peut être détaillée de façon très précise, comme dans ce serment pour Arzens (Aude), vers 1074-1100 :

De ista hora in antea ego Petrus qui fui filius Ermerit fidelis ero ad te Ermengard filia que fuisti Rangarz per drictam fidem sine enganno aisi com debet esse ad suum seniorem cui manibus ses comandaz, et de ista hora in antea non decebrei ni not tolrei ni not vedarei aquel castel qui factus est ni er in alode de Arzenco, ni de las turs ni dels murs ni de las fortezas qui ara $i$ sunt ni adenant factas $i$ serant, ni nols te tolra ni ten tolra, ni nols te vedara ni ten vedara homo nec femina ab meum gen ni ab meo consilio, et per quantas ves tu men comonras per te ipsam aut per tuos missos, in tua postad lo tornarei sine lucro de tuo avere et sine tua deceptione, et si est homo aut homines, femina aut feminas quil te tollat ni ten tollat, vetet aut vetent, finem nec societatem non aurei ab illas neque ab illos ad tuum dampnum me sciente, usque ipsum castrum qui hodie factus est in alode de Arzencs vel in antea erit recuperatum habeas, et adjutor ten serei sine tuo inganno ab ti et sine ti usque recuperatum habeas ipsum castrum, et si recuperare eum potuero, in tua potestate lo tornarei sine lucro de tuo avere et sine tua deceptione. De ista hora in antea adjutor ten serei de totos illos homines et de totas illas feminas de que tu comoniraz per te ipsam aut per tuum missum aut per tuos missos qui tolran tuos fevos nec tuos alodes ni ten tolran, et de illo adjutori non n'enganerai ni mal non ten menarei. Sicut superius scriptum est, si to tenrei tot et to atendrei ego Petrus suprascriptus ad te Ermengard suprascriptam, excepto quantum tu men absolveras tuo graziente animo sine forcia me sciente ${ }^{23}$.

Et surtout, un élément est au centre de l'engagement et en constitue véritablement l'objet : ces textes contiennent tous la promesse de rendre le château, comme dans tous les exemples détaillés ci-dessus, ou comme dans cet autre serment pour le castrum de Blanchefort (Aude, vers 1074-1129) :

Juro ego Willelmus Raimundi filius Ledor a ti Bernardo Atoni filio Ermengardis et tibi Cecilie et filiis vestris Rogerio et Raimundo de ista hora in antea non decipiam de castro de Blancafort, la tor ni las tors, lo mur nils murs, ni las forcas que ara $i$ sunt ne antea factas erunt, nol te tolrei ni ten tolrei, nil te vedarei ni ten vedarei, et per

\footnotetext{
${ }^{22}$ Cartulaire des Trencavel, acte 464, fol. 179.

${ }^{23}$ Cartulaire des Trencavel, acte 287 , fol. $93 \mathrm{v}$.
} 
quantas vegadas tu men comonras per ti ni per tun message, cum forfacto et sine forfacto, lor reddrei et del comoniment no men desvedarei, no men diffugirei, et si nuls hom ou femna, homines vel femine tibi tollerent o ten tolliant, adjutor ten seria ab ti et sine ti senes engant, et si recobrar lo podia, in tua potestate tornar lia sine lucro de avere aut de honore. Sicut in ista carta scriptum est et legi et intellegi potest sine inganno, si to tenrei et to atendre per Deum et hec sancta ${ }^{24}$.

Ce type de serment pour un château instaure donc une hiérarchie : celui qui prête serment reconnaît une autorité supérieure à la sienne sur le castrum qui est l'objet de l'engagement. Le château est un château jurable (on prête serment pour lui) et rendable (celui qui prête serment le détient, mais seulement tant que le seigneur supérieur ne lui demande pas de le rendre $)^{25}$.

Dans la deuxième moitié du XII ${ }^{\mathrm{e}}$ siècle, la forme générale des serments change quelque peu lorsque la forme diplomatique de la charte est réutilisée dans la mise par écrit des serments. Les formulations se font plus précises, voire bavardes, mais le fond des engagements est le même : la promesse de rendre le château à toute semonce et la promesse de fournir une aide militaire. Les textes se présentent alors comme celui-ci, qui est un serment pout La Livinière (Hérault, en 1176) :

Anno Christi incarnationis $M^{\circ} C^{o} L X X V I^{o}$, rege Lodovico regnante. Notum sit omnibus hoc audientibus quod ego Geraldus de Lavineria et ego Willelmus de Carre et ego Bermundus de Campo filii Marie juramus tibi domino Rogerio vicecomiti Biterris filio Saure castrum de Lavineria videlicet turres et forcias omnes et fortalezas quecumque modo ibi sunt et in antea facte fuerint, et quocienscumque castrum illud vel aliquas forcias vel fortalezas de ipso castro per te vel per tuum nuncium nocte vel die recipere volueris, illud tibi nullo modo prohibebimus nec prohibere faciemus et statim in tua potestate sine omni occasione et sine inganno illud mittemus, et nullo modo castrum illud vel aliquid de illo tibi auferemus, et si fuerit homo vel femina, homines vel femine qui tibi castrum illud vel aliquid de illo auferant, cum illo vel cum illa vel cum illis societatem nullo modo habebimus nisi pro castro recuperando, cum omni nostro posse illos vel illas guerreiabimus usquedum castrum illus habeamus recuperatum, et quando castrum illud recuperatum habebimus, statim sine omni mora in tuo posse illud mittemus sine omni lucro honoris et averi quod a te non requiremus. Sicut superius diximus ita tenebimus et observabimus ut melius dici vel intelligi potest ad tuum honorem et utilitatem atque tuorum per hec IIII sancta evangelia. Hujus rei sunt testes [8 noms], Bernardus notarius supradicti domni Rogerii jussione omnium supradictorum hanc cartam scripsit in mense marcii ${ }^{26}$.

Dans tous ces serments, l'engagement est bien une fidélité promise pour un château, castrum ou castellum et qui instaure une hiérarchie. On ne rencontre cependant jamais le terme de fief dans un serment. Pour le trouver, il faut se tourner maintenant vers l'autre grande catégorie de textes qui a été distinguée, les inféodations et les reprises en fief.

Le Midi de la France a conservé les plus anciennes mentions du mot fief dans la documentation, dès l'extrême fin du $\mathrm{IX}^{\mathrm{e}}$ ou le début du $\mathrm{X}^{\mathrm{e}}$ siècle. Je ne prendrai pas en compte ces attestations précoces : elles sont très stéréotypées et apparaissent dans des clauses de

\footnotetext{
${ }^{24}$ Cartulaire des Trencavel, acte 203, fol. 63.

${ }^{25}$ Sur l'importance de la « reddibilité » du château, voir Ch. L. H. Coulson, «Rendability and Castellation in Medieval France », Château Gaillard. Études de castellologie médiévale, t. VI, Caen, 1973, p. 59-67.

${ }^{26}$ Cartulaire des Trencavel, acte 311, fol. 101.
} 
donation où il est interdit de donner en fief. Elles mériteraient une étude à part entière. À partir du XI ${ }^{\mathrm{e}}$ siècle, les occurrences de fevum ou feudum se multiplient. Claudie Amado en a relevé une bonne quarantaine uniquement pour la plaine de Béziers au $\mathrm{XI}^{\mathrm{e}}$ siècle ${ }^{27}$. On voit apparaître dans la documentation des donations en fief. Le fief désigne alors tout type de tenure qu'elle soit aristocratique ou paysanne. Pour cette étude, je n'ai pris en compte que les textes mentionnant un fief sur un castrum ou castellum pour m'en tenir au niveau de l'aristocratie. Dans une étude générale de la société féodale, il faudrait bien entendu intégrer toutes les autres attestations. Si l'on s'en tient à l'aristocratie castrale, les fonds documentaires offrent deux types de textes : tout d'abord des donations en fief ou inféodations. Elles se présentent sous le formulaire classique de la donation, avec le verbe dono, cedo, concedo ou laudo, mais ensuite la façon de donner est qualifiée : ad feudum, ad fevum. On ne donne jamais un fief, on donne un château en fief, comme par exemple dans cette inféodation de Brusque (Aveyron, vers 1027-1077), effectuée par un frère du vicomte Aton II, qui est évêque de Nîmes :

In nomine Domini. Ego Froterius episcopus dono et laudo per fidem et sine inganno tibi Ademarus Corvesinus et posteritati tue ut habeas et teneas tu vel tui de me ad fevum vel de meis ad meum servicium vel veram fidelitatem de me vel de meis scilicet quod totum habeo vel habere debeo in castro quod vocatur Brusca vel in ejus mandamentum ipsius castri $[\ldots]^{28}$

Dès les premières inféodations conservées, la concession n'est absolument pas précaire, mais au contraire héréditaire; c'est explicitement dit dans le texte pour Brusque (ci-dessus : «et posteritati tue »), ou dans un acte d'inféodation du castellum de Calvisson (Gard) par le vicomte Bernard Aton IV, en 1095, 1100 ou 1106 :

In nomine Domini. Scriptura memorialis de dono quod fecit Bernardus Ato vicecomes et uxor sua Cecilia Elziardo de Castriis et infantibus quos de legali uxore habuit, castellum quod Calvuzon nominatur, excepta parte Decani, donavit Bernardus Ato vicecomes et uxore sua Cecilia ad fevum ad totas honores [...]. Istam donationem fecit Bernardus Ato et uxor Cecilia Illiziardo de Castrias in die festivitatis Sancti Andree, in cambra Raimundo Cantarella in presentia [4 noms]. Facta est carta ista feria $\mathrm{VI}^{a}$, luna $I^{a 29}$.

On ne peut détailler ici toutes les conditions qui accompagnent ces donations en fief ; quand elles sont précisées, on trouve l'obligation de prêter serment - ce qui est nommé le serment de reddition, de redditione sacramentum - et la promesse d'aide, c'est-à-dire exactement les clauses contenues dans les textes de serment; très souvent s'y ajoute aussi une albergue, un droit de gîte limité à quelques milites, généralement entre cinq et dix. Si l'on n'avait conservé que ces textes bruts, on pourrait en conclure à une réelle concession du seigneur qui donne en fief. Mais il se trouve que, dans un grand nombre de cas, il est possible de mettre en relation ces textes de donation en fief avec deux autres types de textes, ce qui nous engage à modifier l'interprétation que l'on peut faire du processus féodal.

Un certain nombre de dossiers mieux documentés permet de reconstituer un mécanisme en trois temps pour l'entrée en fidélité. Tout d'abord (logiquement et chronologiquement), le seigneur d'un château donne son château en alleu ; ensuite le seigneur supérieur le lui rend en fief; enfin, le seigneur supérieur reçoit un serment pour ce même

\footnotetext{
${ }^{27}$ op. cit., t. 1, p. 155-175, et surtout p. 418-426.

${ }^{28}$ Cartulaire des Trencavel, acte 474, fol. 185.

${ }^{29}$ A. Germain, LIM, acte 368.
} 
château. Une telle reprise en fief a été opérée en 1085, 1091 ou 1096 pour le castellum de Caissargues en Nîmois :

Hec est carta donacionis quam fecit Ugo Berengarius et uxor sua Aimildis et infantes illorum ad Ermengardam vicecomitissam et Bernardum Atonem filium suum et ad illum qui de illo exibit qui vicecomes erit de Nemauso civitate vel ad filiam que vicecomitissa erit similiter de Nemauso. Hic Ugo suprascriptus et uxor sua et infantes illorum donant ad Ermengardam vicecomitissam et ad filium suum partem suam quam habent in castello de Caxanicis et totos retornos et convenientias quas ibi Ugo Berengarius habet et obvenire ei ibi sunt ad alodem et totum suum alodem ubicumque eum habeat quem modo habet vel in antea illi advenire est, in tale vero racione quod ipsa Ermengardis vicecomitissa vel Bernardus Ato filius suus vel filius suus qui vicecomes sit de Nimis vel filia que vicecomitissa sit de Nimis donet ad fevum hunc honorem suprascriptum et ad beneficium ad Ugonem Berengarius et ad uxorem suam et ad infantes infantum suorum usque in perpetuum ad to[t]as onores ${ }^{30}$.

Sur un même parchemin, on été ici recopiées la donation en alleu et la restitution en fief. Le serment correspondant, copié sur une autre feuille, est aussi conservé mais a été totalement déclassé dans le fonds d'archives - ce serment est en tous points comparable à ceux qui ont été vus plus haut ${ }^{31}$. Un autre exemple est plus étonnant d'un point de vue archivistique, une reprise en fief du château de Bernis le 14 mars 1101. La donation en alleu et la restitution en fief sont copiées dans le cartulaire des Trencavel, mais le serment correspondant n'y a pas été copié : il est conservé à l'état d'original dans le Trésor des chartes ${ }^{32}$. Cela entraîne à penser que, lorsqu'on ne possède pas les trois actes d'une reprise, on peut craindre des pertes documentaires. Dans certains cas en effet, on n'a pas conservé les trois étapes du processus mais seulement deux (par exemple, on conserve la donation et la restitution mais on a perdu le serment; ou bien on a une donation en alleu puis un serment). Ce dernier cas de figure peut être illustré par le cas du castellum de Castries (Hérault) en 1095 :

Breve donationis que fecit Ramun, filii Viola, et uxori sua Gersende, filia Froiles, en Raimundo et en Bertrando filius suus. E Raimundus et Bertrandus suprascriptus, filii Garsendis, dona[n]t castellum de Castrias ad alo a Dalmaz, filium Aizivella et de ipsas fortezas que ibi sunt et adenantea factas erunt per fidem et sine enganno cum consilio Raimo et Garsenz, in presentia [3 noms]. Actum est hoc $V$ idus septembris, anno XXXV regnante rege Philippo.

Serments correspondants :

Audis tu Dalmas filius Aizivella ego Raimundus filius Garsendis lo castello de Castrias, las fortezas que ibi sunt et in antea facte erunt, ego non las te tolrai, ni ten tolrai... in tua postat lo tornaria...

Audis tu Dalmas filius Aicivella ego Bertrandus filius Garsendis lo castel de Castrias, las fortezas que ibi sunt et in antea ibi erunt factas, ego non las ti tolrai, ni ten tolrai... in tua postat lo tornaria... ${ }^{33}$

\footnotetext{
${ }^{30}$ Paris, Archives Nationales, J 322, 81.

${ }^{31}$ Serment correspondant : Paris, Archives Nationales, J 304, 98

${ }^{32}$ Donation en alleu et restitution en fief : cartulaire des Trencavel, acte 565, fol. 220v ; serment correspondant : Paris, Archives nationales, J 322, 94.

${ }^{33}$ Respectivement : A. Germain, LIM, actes 383, 384 et 385.
} 
Parfois, ce n'est pas une donation qui inaugure la procédure, mais une vente : on peut alors parler de reprise en fief monnayée, comme le cas du château de Montaigu en Albigeois vers 1030-1060 ou du château de Termes en $1118^{34}$.

Tout cela incite à penser que les aléas de la conservation des sources rendent assez illusoire pour nous de décider dans tous les cas s'il s'agit d'une reprise en fief ou d'une véritable inféodation. Quand on n'a conservé qu'un seul des textes, que peut-on dire ? Une inféodation seule ou un serment isolé peuvent être les seules pièces subsistantes d'un processus de reprise en fief. Ou bien si l'on ne conserve que la donation en alleu, il est difficile de croire que les seigneurs châtelains se sont entièrement défaits de leurs droits sur le château ; bien souvent, d'ailleurs, on retrouve des serments à la génération postérieure. Dans ces circonstances, il semble impossible de distinguer radicalement les deux types documentaires, inféodation et reprise. D'autant plus qu'un autre phénomène vient ajouter à la complexité : on a parfois conservé plusieurs reprises en fief successives sur un même château ${ }^{35}$. Par exemple, le château de Sénégats en Albigeois est repris en fief des Trencavel en 1124 et en 1144. On a vu plus haut le cas de Bernis en 1101 : une nouvelle reprise en fief est effectuée en 1154. Chez les Guilhem de Montpellier, il y a aussi des reprises en fief successives pour Popian, le Pouget ou Castries.

De telles reprises en fief successives pourraient paraître absurdes si l'on considérait la cession de l'alleu comme une transaction foncière dans la tradition romaine. On ne pourrait pas donner à nouveau ce que l'on n'a plus, ce qui a déjà été donné à la génération antérieure. Cependant, les textes ne disent pas que les seigneurs châtelains donnent l'alleu, mais qu'ils donnent en alleu. Ce n'est pas le contenu de la donation qui est qualifié d'alleu, mais la modalité de celle-ci : donner en alleu semble vouloir dire entièrement, complètement, avec tous les droits et tout le pouvoir. Une reprise en fief ne se distingue finalement d'un simple serment que par une sorte de solennité particulière; la reprise en fief n'est qu'une façon particulièrement solennelle de reconnaître l'autorité du seigneur supérieur. Elle peut être renouvelée à chaque génération.

Un autre élément pourrait nous aider à comprendre les successions de reprise, mais malheureusement l'histoire politique du Languedoc aux XI ${ }^{\mathrm{e}}-\mathrm{XII}^{\mathrm{e}}$ siècles est assez mal connue dans ses détails. Plusieurs de ces reprises en fief sont en effet renouvelées après un épisode de revirement politique, ce que nous appellerions une trahison (un engan ou une bauza, disent les textes). Le cas le plus évident est celui de Bernis déjà évoqué : on a conservé entre les deux reprises en fief des Trencavel, de 1101 et 1154, une reprise en fief du comte de Toulouse en 1138. On peut reconstituer un scenario plausible : les seigneurs de Bernis étaient dans l'orbite des Trencavel ; ils se sont alliés en 1138 à leurs ennemis de Toulouse dans une circonstance de la grande guerre méridionale dont le détail nous échappe; puis dans une période d'apaisement, ils sont revenus dans l'alliance Trencavel en 1154. On peut se demander combien d'autres péripéties de ce type restent dans l'ombre; elles permettraient de mieux comprendre ces répétitions de reprises en fief.

Ces analyses conduisent à proposer quelques réflexions sur le fonctionnement de l'aristocratie castrale languedocienne. À partir du XI ${ }^{\mathrm{e}}$ siècle, les sources montrent des familles seigneuriales qui détiennent des châteaux, qu'elles ont vraisemblablement construits. À un certain moment, ces seigneurs castraux trouvent intérêt à reconnaître l'autorité d'un seigneur supérieur, ou bien, dans certains cas, ils y sont contraints : il s'agit bien souvent du résultat d'un rapport de force. La reprise en fief - que ce soit la première ou un renouvellement, peu

\footnotetext{
${ }^{34}$ Montaigu (Tarn) : cartulaire des Trencavel, acte 46, fol. 11 ; Termes (Aude) : cartulaire des Trencavel, acte 190, fol. 60.

${ }^{35}$ Voir l'analyse de Fredric L. Cheyette, «On the fief de reprise », Les sociétés méridionales à l'âge féodal, Hommage à Pierre Bonnassie, H. Débax (éd.), Toulouse, 1999, p. 319-324.
} 
importe, il est impossible de les distinguer-, l'inféodation ou le serment manifestent l'engagement d'une nouvelle génération au service du seigneur supérieur, engagement essentiellement centré sur le château et la promesse d'aide militaire. Il est toujours clairement juré que le château sera rendu à toute semonce du seigneur. Entre deux semonces, le châtelain est bien le seigneur du château; en revanche si on le lui réclame, il est obligé de le rendre.

Les textes de reprise en fief montrent aussi la force de ces lignages seigneuriaux. Les seigneurs castraux entrent dans la dépendance d'un seigneur supérieur, mais ils ont la possibilité de lui imposer un certain nombre de contraintes, du moins dans le cas des lignages les plus puissants. La reprise en fief manifeste bien un transfert du pouvoir sur le château, mais ce transfert peut être soumis à des conditions : la plus courante est qu'il est interdit au seigneur supérieur de remettre ce pouvoir qui vient de lui être reconnu à qui que ce soit d'autre que ses descendants. Les formulations de ces contraintes ou conditions peuvent varier : à Caissargues, il est interdit au vicomte de céder le château repris en fief à quiconque d'autre qu'un successeur qui serait vicomte de Nîmes.

[...] In tale vero conveniencia donat hunc honorem Ugo Berengarius et uxor sua et infantes sui ad vicecomitissam et ad Bernardum Atonem filium suum quod ipsa Ermengarda vel Bernardus Ato filius suus vel ipsi qui vicecomites erunt de Nimis per sugcedemento vel filia que vicecomitissa erit per sugcedemento, donare neque vindere neque inpignorare neque aliquo modo incobolare alicui homini vel femine possit, neque ad sanctos neque ad sanctas. Et si aliquis vicecomes vel aliqua vicecomitissa hoc fecerit, hic honor suprascriptus revertatur ad Ugonem Berengarium vel ad proximos suos ad alodem sine blandimento ullius hominis vel femine. Hanc donacionem ideo facit Ugo Berengarius et uxor sua et infantes sui ad vicecomitem et ad vicecomitissam ut eum et suos manuteneant et totum suum honorem. Facta carta ista in die mercurii XIIII kalendas julii, regnante Philipo rege [signa...] $]^{36}$

À Calvisson, l'exemple paraît encore plus significatif puisqu'il s'agit formellement d'une inféodation : le vicomte se voit imposer le fait qu'il ne pourra pas transférer le pouvoir à un autre seigneur :

[...] cum tali conveniencia quod Bernardus Ato aut uxor ejus Cecilia non mitant alium dominum super Eliziardo extra se et heredes suos. Istam donationem fecit Bernardus Ato et uxor Cecilia Illiziardo de Castrias in die festivitatis Sancti Andree, in cambra Raimundo Cantarella in presentia [4 noms]. Facta est carta ista feria VI ${ }^{a}$, luna $I^{a}{ }^{37}$.

Cela signifie clairement que le vicomte devra rester le seigneur direct et qu'il lui est interdit d'intercaler un degré dans la hiérarchie de la fidélité sur le château. Et surtout à Caissargues, il est bien dit que, si le vicomte dérogeait à la règle qui lui est imposée, les seigneurs qui effectuent la reprise en fief récupèreraient leur château en alleu. À la fin du XII ${ }^{\mathrm{e}}$ siècle, quand les chartes deviennent plus détaillées et plus précises, la même idée est exprimée de façon encore plus claire : il est explicitement interdit d'introduire un seigneur intermédiaire, sinon la reprise en fief serait caduque et le bien donné retournerait à son précédent statut, une détention en alleu :

Ego Bernardus de Muro Vetulo et ego Berengarius et ego Bermundus nos tres fratres

\footnotetext{
${ }^{36}$ Suite du texte cité plus haut, référence à la note 29.

${ }^{37}$ A. Germain, LIM, acte 368.
} 
simul per nos et per Gaucelinum fratrem nostrum et heredes nostros bona fide et sine dolo cum hac carta donamus et tradimus nunc et in perpetuum pro alodio tibi domino Rogerio vicecomiti Biterris et heredi vel heredibus tuis qui villam sive civitatem Biterris habuerint et quicquid habemus vel aliquo modo habere debemus in castello de Muro Vetulo et in ejus terminiis et inde facimus tibi hominium ego Berengarius et ego Bermundus. Et ego Rogerius predictus accipio vos fratres pro hominibus et fidelibus et dono vobis omnibus prenominatis fratribus et trado et heredibus vestris in perpetuum per me et heredes meos ad feudum honoratum ad omnes honores totum honorem vestrum predictum quem mihi dedistis pro alodio in castello de Muro Vetulo et in ejus terminiis. Pro quo feudo facietis mihi et heredibus meis singulis annis tantummodo alberga quinque militum et promitto quod donum predictum quod mihi de vestro fecistis non dabimus ego vel heredes mei alicui vel aliquibus hominibus seu feminabus, nisi tamen illi vel ille heredum nostrorum qui villam sive civitatem de Biterris habuerint, nec aliquem hominem vel feminam medium vel mediam in hoc dono umquam vos ponemus, et si forte alicui homini vel femine ego vel heredes mei de predicto honore vestro vel de hoc quod inde vobis habemus fecerimus donum, quod vos honorem vestrum libere et sine vinculo hominii, sicut habebatis, habeatis, et totum donum predictum ad pristinum statum reducatur ${ }^{38}$.

La relation féodale est donc un statut instauré, soumis à des conditions, nullement pérenne. Le fief n'est fief que tant que perdure le lien entre les deux protagonistes du serment, de l'inféodation ou de la reprise. Guilhem V de Montpellier, avant de partir pour la conquête de Majorque, en 1114, peut ainsi en guise de donatio pro anima rétrocéder en alleu des châteaux qu'il avait inféodés : s'il meurt en Espagne, les seigneurs castraux redeviendront alleutiers.

Illa vero castella, videlicet Frontinianum, Monbasen et Popianum cum omni alodio quod acaptavi et adquisivi cum ipsis castellis ubicumque sit, et Cornunsec et Montemferrarium cum omni alodio quod in eis et in eorum terminio habeo, reddo, solvo et guirpisco per alodium omnibus illis qui per manum meam ad fevum habent, eis et eorum successorum ${ }^{39}$.

Sur la question du fief et de la vassalité, quelques conclusions émergent de ces réflexions. Il semble qu'il y a très peu de fiefs véritablement donnés par le seigneur supérieur; en ce qui concerne l'aristocratie castrale pour le moins, le fief ne peut se penser comme une concession du seigneur. Le fief n'est pas une unité de propriété, un terroir ou un espace, c'est une relation, un lien institué ${ }^{40}$. Donner ou recevoir en fief, c'est établir une relation hiérarchique sur un château. Cet état de fait éclaire une formulation étonnante qui paraît dans tous les serments pour un château : le fidèle s'engage pour ce qu'il a, mais aussi

\footnotetext{
${ }^{38}$ Cartulaire des Trencavel, acte 452, fol. 172.

39 Testament de Guilhem V : cartulaire de Maguelone, acte 38, à la p. 779 (Frontignan, Montbazin, Popian, Cournonsec et Montferrier, aujourd'hui dans l'Hérault). La même pratique, que l'on pourrait qualifier « après moi, le déluge », est attestée dans la vicomté de Narbonne : dans des circonstances difficiles pour elle, la vicomtesse Ermengarde «achète » en 1193 l'aide militaire d'un seigneur châtelain, Ermengaud de Fabrezan, en abandonnant après sa mort le serment et la reddition qu'il était tenu de faire pour son castrum au seigneur de Narbonne. Fabrezan redeviendra donc un alleu (texte cité en annexe V de l'article de Jacqueline Caille, « Ermengarde, vicomtesse de Narbonne (1127/29-1196/97) Une grande figure féminine du Midi aristocratique », La femme dans l'histoire et la société méridionales (IX ${ }^{e}-X I X^{e}$ siècle), Actes du $66^{\circ}$ Congrès de la Fédération Historique du Languedoc méditerranéen et du Roussillon, Narbonne, 1995, p. 42).

${ }^{40}$ Voir notre thèse, La féodalité languedocienne, op. cit., p. 144-148.
} 
pour ce qu'il aura dans le château ${ }^{41}$. La promesse s'applique par avance aux constructions futures. Le fief est bien l'expression d'une relation de fidélité, dont le castrum est la base matérielle. Cela permet de comprendre l'absence du mot «fief» dans les serments. Le serment est toujours simplement fait pour le château, castrum ou castellum. Ce château n'est pas un fief, il est tenu en fief ; et le retour à une détention allodiale est toujours possible, comme nous venons de le voir. Le serment est la cérémonie qui instaure la relation féodale. Bien plus, celui qui jure prête toujours pour le castrum, or on sait parfois pertinemment qu'il n'en détient qu'une petite partie (par exemple, on a souvent plusieurs serments contemporains pour un même château, ou bien on a une reprise en fief pour la moitié, le tiers, une part du château ${ }^{42}$, alors que le serment correspondant mentionne uniquement le castrum ou castellum en bloc). Le seigneur châtelain ne peut pas être fidèle pour une moitié ou un tiers de château, il doit défendre le château tout entier. Ce castrum pour lequel on prête serment joue donc essentiellement comme une sorte de fiction juridique qui sert de base à la fidélité ; ce castrum peut être considéré comme une unité de compte de la fidélité.

Qu'en est-il de la vassalité ? Le mot « vassal » n'apparaît jamais en Languedoc, où on trouve homo ou fidelis, mais pas vassallus; ce qui est généralement compris sous le terme de vassal existe cependant en Languedoc. On peut dire que la vassalité est le lien personnel instauré au moment où la relation féodale est conclue, entraînant droits et devoirs. Dans le Languedoc des $\mathrm{XI}^{\mathrm{e}}-\mathrm{XII}^{\mathrm{e}}$ siècles, la vassalité ne préexiste pas à l'instauration du fief. Être vassal n'est pas une réalité abolue, mais toujours relative à un château. Tous les seigneurs châtelains d'une certaine importance ont plusieurs châteaux et souvent plusieurs seigneurs pour leurs différents châteaux. Il peut y avoir aussi plusieurs seigneurs supérieurs pour le même château. Même au plus haut niveau de l'aristocratie, les Trencavel par exemple ont pour seigneurs les comtes de Toulouse à Albi, Nîmes, Agde et Béziers et les comtes de Barcelone pour Carcassonne et Razès. Les Guilhem ont pour seigneurs au moins le comte de Melgueil, l'évêque de Maguelone, le vicomte Trencavel et le comte de Barcelone. À l'inverse, un vicomte, par exemple, n'est pas le seigneur supérieur dans toute sa vicomté. Pour reprendre l'exemple des Trencavel, ils n'ont réussi à contrôler qu'une petite partie de la vicomté de Nîmes autour de la cité, alors que la région des Cévennes est dans la domination des seigneurs d'Anduze-Sauve. Mais par ailleurs, les Trencavel contrôlent les châteaux dans le sud-ouest du Rouergue où ils concurrencent la domination des vicomtes de Millau ou des comtes de ROuergue. Cela donne une image de réseaux de fidélité enchevêtrés et coalescents, mais aussi tangents. En Languedoc, la métaphore de la pyramide féodale n'a aucune efficience.

La complexité est encore accrue par le fait que ces seigneurs ne contrôlent que très rarement la totalité d'un château : partout il y a des groupes de frères, de cousins, de parents. En effet, le droit successoral est demeuré égalitaire jusqu'au XII ${ }^{\mathrm{e}}$ siècle au moins. À chaque génération, on partage les droits sur les châteaux. Bien évidemment, ces divisions n'ont pas vocation à se multiplier à l'infini; il y a aussi sans cesse, de façon concomitante, des disparitions de branches sans héritiers, des déchéances, des réunifications. L'aristocratie castrale a généralement des fractions de droits dans plusieurs châteaux, et chaque château connaît sa propre situation de seigneurie. Cet état de fait entraîne immanquablement des conflits de fidélité, quand deux seigneurs supérieurs sont en guerre, par exemple : ces conflits sont réglés au coup par coup, par des rapports de force ou par des négociations. Il n'y a pas d'institution équivalente à la ligesse, mais la souplesse du serment et de ses clauses modulables permet d'introduire très fréquemment une clause de réserve de fidélité : on prête

\footnotetext{
${ }^{41}$ Voir les serments ci-dessus : de ipsas turres ni de ipsas fortezas que ibi hodie facte sunt aut in antea facte erunt.

${ }^{42}$ Voir le cas de Caissargues, ci-dessus.
} 
serment à quelqu'un pour un château, sauf contre tel ou tel. Ce sont des réseaux de fidélité enchevêtrés, mais aussi hiérarchisés.

L'hommage doit sembler jusqu'ici bien absent à l'historien familier des descriptions classiques. Pourtant, le Languedoc est la région qui fournit les attestations parmi les plus anciennes de hominium, hominaticum ou homenesc (à partir d'environ 1035). Un des serments retranscrit ci-dessus fait aussi apparaître la fameuse clause d'origine carolingienne « sicut homo debet esse seniori suo ». Il est à remarquer que cette clause est parfois traduite en occitan et comme digérée par la pratique locale : aisi com debet esse ad suum seniorem cui manibus ses comandaz ${ }^{43}$. Une inféodation pour Castries à la fin $\mathrm{du} \mathrm{XI}^{\mathrm{e}}$ siècle dit que le fidèle doit être «l'homme des deux mains ». Une autre inféodation du côté de Muret en Toulousain vers 1060-1090 dit «l'homme les mains jointes». On a donc d'assez fréquentes mentions d'hommage à partir du troisième tiers du $\mathrm{XI}^{\mathrm{e}}$ siècle. Mais l'hommage ne semble pas être systématique. Il se peut que les textes entraînent à sous-estimer la part de l'hommage, car il s'agit d'un rite qui est fait et qui n'a pas besoin d'être dit, ni décrit : les actes pourraient donc ne le mentionner qu'incidemment.

Mais, plus globalement, on peut s'interroger sur la nécessité de l'hommage dans le lien féodo-vassalique. F. L. Ganshof avait fait de la trilogie hommage-serment-investiture une sorte de dogme. Or il est certain qu'il n'y a pas d'investiture, ni de rite d'investiture en Languedoc. À sa place, on trouve de très nombreuses chartes d'inféodation ou de reprise en fief qui décrivent la concession, son contenu et les conditions qui sont mises à la tenure du fief. Quant à l'hommage, c'est une cérémonie parmi d'autres ; la prestation de serment ellemême est pourvue d'un rituel codifié et complexe ${ }^{44}$. On trouve des inféodations avec et sans hommage, sans qu'il y ait de différence dans les contraintes imposées au vassal. Par ailleurs, dans l'Occident tout entier, l'hommage peut s'appliquer à bien d'autres objets qu'à la relation féodale et il est investi de bien d'autres contenus que l'entrée en vassalité, que l'on pense à l'hommage en marche ou à l'hommage de paix ${ }^{45}$.

Nous présenterons un dernier texte pour illustrer la singularité des réalités languedociennes : une controverse de 1122 sur le château de Brissac (Hérault).

Hec est carta difinicionis super controversiis que fuerunt inter Guilelmum abbatem secundum Gellonensis cenobii et Assalit de castro Breixach. Abbas enim dicebat quod supradictus Guilelmus Assaillith debebat facere ei non solum hominium set eciam jurare fidelitatem pro feudo quem ab eo tenebat. Guilelmus vero Assaillit hominium quidem profitebatur set sacramentum fidelitatis negabat. [Pons, frère de Guilhem, vient témoigner] Confessus est in placito sacramentum fidelitatis debere fieri a domino de Breixac abbati Gellonensi pro feudo quem ab ipso tenebat, et eciam idem Pontius paratus fuit illud sacramentum fidelitatis facere propria manu. Unde Guilelmus Assaillit, adquiescens veritati, juravit propria manu fidelitatem supradicto abbati $^{46}$.

\footnotetext{
${ }^{43}$ Voir ci-dessus le serment pour Arzens.

${ }^{44}$ Voir notre article : «Le serrement des mains. Éléments pour une analyse du rituel des serments féodaux en Languedoc (XI ${ }^{\mathrm{e}}-\mathrm{XII}{ }^{\mathrm{e}}$ siècles) », Le Moyen Age, 2007/1, p. 9-23.

${ }^{45}$ Voir Klaus Van Eickels, «Homagium and amicitia: Rituals of Peace and their Significance in the AngloFrench Negociations of the Twelfth Century », Francia, Band 24/1, 1997, p. 133-140 ; Paul Hyams, « Homage and Feudalismus: a Judicious Separation », Die Gegenwart des Feudalismus, Présence du féodalisme et présent de la féodalité, The Presence of Feudalism, P. Monnet N. Fryde, O. G. Oexle (éd), Vandenhoeck \& Ruprecht, Göttingen, 2002, p. 13-49.

${ }^{46}$ Cartulaire de Gellone, acte 364 ; suivi par le serment pour le château : acte 365.
} 
L'hommage est donc un rite qui peut intervenir dans la relation féodo-vassalique, mais qui n'est pas consubstantiel à cette relation. En Languedoc au moins, un serment pour le fief suffit.

La société languedocienne des $\mathrm{XI}^{\mathrm{e}}-\mathrm{XII}{ }^{\mathrm{e}}$ paraît bien être une «société féodale ». Le lien féodal détermine des réseaux et des hiérarchies à l'intérieur de l'aristocratie castrale. Il n'est nullement contradictoire avec l'existence d'autres liens, en particulier de liens de parenté, qu'elle soit charnelle ou spirituelle ${ }^{47}$. On observe en Languedoc une continuité de la classe dirigeante depuis ce que l'on peut connaître de l'aristocratie de l'époque caroligienne jusqu'à l'époque féodale. Cela ne veut pas dire exactement une continuité biologique. Ceux qui peuvent construire des tours et des châteaux au $\mathrm{XI}^{\mathrm{e}}$ sont les héritiers ou les descendants des grandes familles qui avaient le pouvoir au $\mathrm{IX}^{\mathrm{e}}$ ou au $\mathrm{X}^{\mathrm{e}}$, autant que l'on puisse en juger. Il n'y a pas d'anarchie, ni d'anarchie féodale. Au contraire le lien féodal a permis de reconstituer des hiérarchies. Mais tout a changé. Au $\mathrm{XI}^{\mathrm{e}}$ siècle, le pouvoir émane du château, il est fondé sur le château. La transition ne s'est pas opérée dans une courte phase de crise violente, comme en Catalogne ${ }^{48}$. Le bouleversement n'en est pas moins profond. L'aristocratie se restructure au $\mathrm{XI}^{\mathrm{e}}$ siècle dans une juxtaposition de segments de fidélité fondés sur le fiefcastrum. Ce qui a changé radicalement, c'est le mode de circulation du pouvoir à l'intérieur de cette aristocratie. Dans le contexte féodal, le pouvoir n'est plus délégué comme il pouvait l'être dans le cadre carolingien et post-carolingien, désormais il ne peut être que partagé ${ }^{49}$. Et c'est bien la fonction des inféodations et des reprises en fief que d'entériner ce partage.

Hélène Débax

Université de Toulouse CNRS-UMR 5136 Framespa-Terrae

\footnotetext{
${ }^{47}$ Voir à ce propos Jean-Pierre Devroey, Puissants et misérables. Système social et monde paysan dans l'Europe des Francs, Bruxelles, Académie royale de Belgique, 2006.

${ }^{48}$ Voir Pierre Bonnassie, La Catalogne, op. cit., et «Du Rhône à la Galice : genèse et modalités du régime féodal », Structures féodales et féodalisme dans l'Occident méditerranéen (X'-XIII siècles), Rome, 1980, p. 1755 .

${ }^{49}$ Je reprends ici l'heureuse formule de Thomas Bisson («The "Feudal Revolution" », Past and Present, vol. 142, 1994, p. 36-37).
} 
Fig. 1 : Châteaux des $\mathrm{IX}^{\mathrm{e}}-\mathrm{X}^{\mathrm{e}}$ siècles

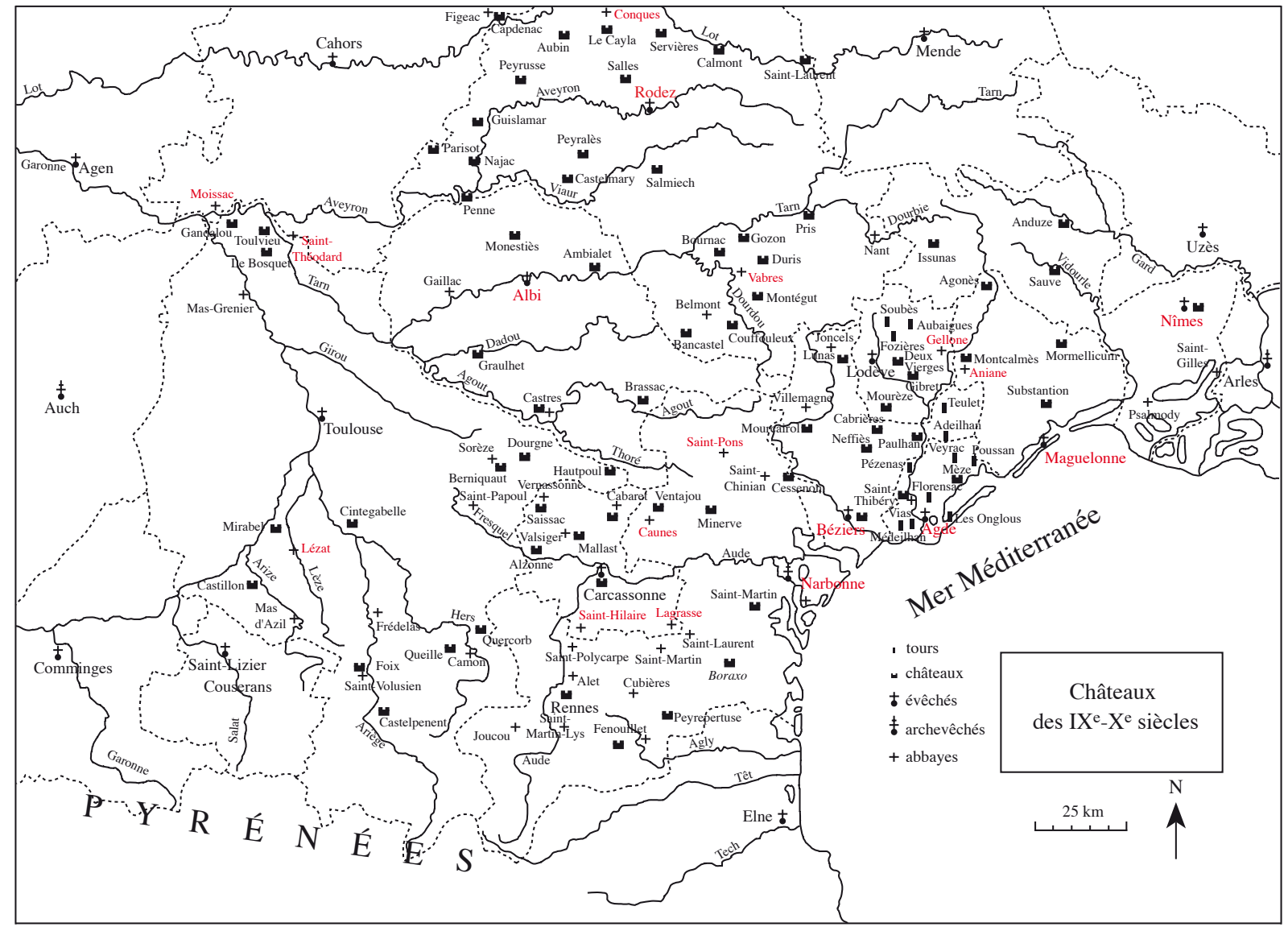


Fig. 2 :

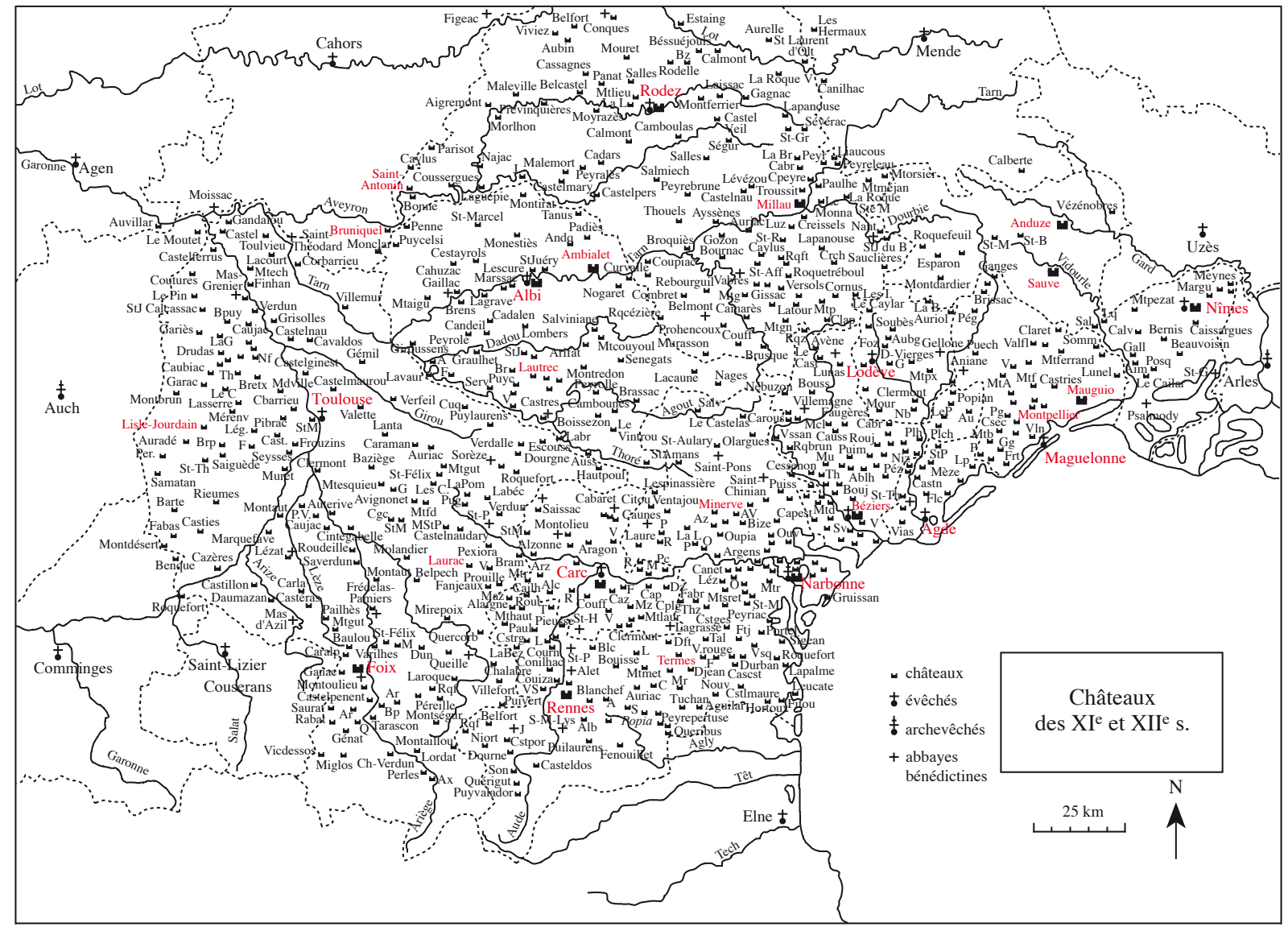

